San Jose State University

From the SelectedWorks of Stoyu I. Ivanov

2016

\title{
Analysis of the factors impacting ETFs net fund flow changes
}

Stoyu I. Ivanov, San Jose State University

Available at: https://works.bepress.com/stoyu-ivanov/42/ 


\title{
Analysis of the Factors Impacting ETFs Net Fund Flow Changes
}

\author{
Stoyu I. Ivanov, Ph.D. \\ Nancie Fimbel Investment Fellow \\ Associate Professor \\ Accounting and Finance Department \\ Lucas College and Graduate School of Business \\ One Washington Square \\ San Jose State University \\ San Jose, CA 95192-0066
}

\begin{abstract}
Purpose - The purpose of this study is to identify the factors that impact the exchange traded funds net fund flow changes on daily basis.

Design/methodology/approach - We study 1,212 different exchange traded funds with a proprietary daily net fund flow data and logistic regressions because the majority of the 1,212 exchange traded funds have mostly zero daily net fund flow changes.

Findings - We document that in the period December 22, 2005 to July 28, 2010 autocorrelation at the daily frequency is not universally present for the 1,212 exchange traded funds that we study, despite the fact that this is the case in the monthly data documented in prior studies. We also fail to find support for the feedback trading hypothesis but find some support for the contrarian investor hypothesis on daily basis, even though the opposite is ascertained for both in the prior literature monthly data. Also, we cannot conclude that tracking error prompts net fund flow changes and thus arbitrage activity.

Originality/value - The paper contributes to the ongoing analysis of the factors influencing investment companies fund flow changes, which has mostly focused on open-end funds and monthly data so far. Considering the increased scope and relevance of exchange traded funds in today's financial markets this study fills a void in the fund flow changes literature.
\end{abstract}




\section{Introduction}

We address the following research question - what exogenous factors motivate the changes in exchange traded fund (ETF) net fund flows (NFF). To the best of our knowledge this is the first study to examine this issue on daily basis and for a large number of ETFs, we study 1,212 different ETFs. ETFs are an interesting topic due to their explosive growth in the past decade. The Investment Company Institute (ICI) reported \$1.73 trillion in assets by 1,333 ETFs in April of 2014 compared to $\$ 1.46$ trillion in assets by 1,209 ETFs in April of 2013. The Spider (Ticker: SPY), the Diamonds (Ticker: DIA) and the Cubes (Ticker: QQQ) the oldest and some of the most popular ETFs hold approximately $13 \%$ of all ETF assets. The SPY, DIA and QQQ are the S\&P 500, Dow Jones Industrial Average (DJIA) and NASDAQ 100 tracking ETFs, respectively. The SPY is designed to be $1 / 10$ of the S\&P500 index, the DIA, 1/100 of the DJIA, and the Cubes $1 / 40$ of the NASDAQ- 100 .

In the US, ETFs legally are registered as either open-end funds or unit-trusts. ETFs gained popularity, because similar to index funds, are index tracking securities with intradaily price changes. The US based ETFs are physical ETFs whereas the majority of ETFs in Europe are synthetic. The difference between physical and synthetic ETFs is that physical ETFs hold all or portion of the securities of the underlying index, whereas the synthetic ETFs use derivatives, such as swaps, to replicate the performance of the index (Fassas, 2014). In this study we focus solely on US based ETFs, since we have only US ETF data.

ETFs' most appealing features are diversification, cost and tax efficiency. Even though, ETFs are similar to common stock in that they pay out dividends and trade at intradaily prices ETFs also differ from common stock in that they do not have short-selling restrictions (Alexander, and Barbosa 2005; Yu 2005). Typically, ETFs have a net asset value (NAV) of the securities in their portfolio and stock exchange determined ETF share price that are close because an "Authorized Participant" is designated by the ETF sponsor to arbitrage between the price of the ETF and the value of the underlying portfolio. The "Authorized Participants" are typically large institutional investors who are allowed to create or redeem ETF shares with the ETF sponsor in pre-specified quantities called creation/redemption units. These creations/redemptions are considered "in-kind transfers" for IRS purposes and thus have no net cost or tax impact. This "in-kind" creation/redemption process ensures that the ETF price is close to its NAV. If there is a difference, a profit-making arbitrage opportunity arises and the "Authorized Participant" can create/redeem shares and make a profit. Thus, it is not surprising to find in the ETF literature that on monthly basis ETF NFF are autocorrelated, Kalaycioğlu (2004). There are numerous studies documenting autocorrelation in monthly mutual fund NFF, Ippolito (1992), Warther (1995), Gruber (1996) and Sirri and Tufano (1998). Kalaycioğlu (2004) documents that monthly NFF changes are motivated by past ETF performance. This study is different from the Kalaycioğlu (2004) study in that Kalaycioğlu uses monthly flow data, whereas we use daily flow data. Also, Kalaycioğlu does not have NFF data but rather computes the ETF NFF based on the difference between current and past month ETF shares outstanding. This paper is also different from the Kalaycioglu study in that we use a logistic model specification whereas Kalaycioğlu uses Ordinary Least Squares (OLS) regressions. 
Nevertheless, we examine if the relations identified in the prior literature hold in daily data. Additionally, the difference between the NAV and the ETF price is called tracking error and naturally suggests that NFF would change when such activity is performed due to ETF creation/redemption. Numerous studies examine ETF tracking error, Gastineau (2004) and Elton, Gruber, Comer and Li (2002) to name a few, but this is the first study to examine if there is such relation empirically. The hypotheses tested in this study and findings are presented in Table 1.

Table 1. Hypotheses Description and Results.

\begin{tabular}{|l|l|l|l|}
\hline Hypothesis & Description & Expectation & Findings \\
\hline H1-0 & $\begin{array}{l}\text { NFF changes have no first-order } \\
\text { autocorrelation }\end{array}$ & Reject & Fail to Reject \\
\hline H2-0 & $\begin{array}{l}\text { NFF changes are not related to past } \\
\text { ETF returns }\end{array}$ & Reject & $\begin{array}{l}\text { Fail to Reject for some } \\
\text { Reject for Others }\end{array}$ \\
\hline H2A-0 & $\begin{array}{l}\text { NFF changes are not positively } \\
\text { related to past market performance } \\
\text { (Feedback Trader Hypothesis) }\end{array}$ & Reject & Fail to Reject \\
\hline H2B-0 & $\begin{array}{l}\text { NFF changes are not negatively } \\
\text { related to past market performance } \\
\text { (Contrarian Investor Hypothesis) }\end{array}$ & Reject & $\begin{array}{l}\text { Fail to Reject for some } \\
\text { Reject for Others }\end{array}$ \\
\hline H3-0 & $\begin{array}{l}\text { NFF changes are not related to past } \\
\text { ETF tracking error }\end{array}$ & Reject & Fail to Reject \\
\hline
\end{tabular}

We document that extrapolating the evidence in the existing literature that the NFF are autocorrelated on monthly basis might not be appropriate at the daily frequency level. We also fail to find support for the feedback trading hypothesis but find some support for the contrarian investor hypothesis on daily basis, even though the opposite is ascertained for both in the prior literature monthly data. Also, using the daily data we cannot conclude that tracking error prompts arbitrage activity by using creation and redemption of ETF units, even though the way ETFs are designed this is a natural assumption. This naturally cannot be interpreted as suggesting that arbitrage does not exist using other derivative instruments.

\section{Literature Review}

This study extends the work of Ippolito (1992), Warther (1995), Gruber (1996), Sirri and Tufano (1998), Kalaycioğlu (2004) and Boney, Doran and Peterson (2007). Ippolito (1992) examines mutual fund investors' flows in and out of mutual funds in response to the mutual fund's performance. He documents and justifies that this is the rational behavior of mutual fund investors. In a related study, Warther (1995) examines fund flows in response to mutual fund performance but on aggregate, macro, mutual fund categories level. Warther (1995) documents that fund flows are related to subsequent returns, and also that returns are related to subsequent flows, positively and negatively, respectively. Kalaycioğlu (2004) is one of a few studies examining ETF flows. The only other study in the area of ETF flows is Boney, Doran and Peterson (2007). Both Kalaycioğlu (2004) and Boney, Doran and Peterson (2007) use a formula to determine the mutual fund flows because they have no access to fund flows data. They use the estimation of mutual fund flows method set in Gruber (1996) and Sirri and Tufano (1998). Both 
Kalaycioğlu (2004) and Boney, Doran and Peterson (2007) document autocorrelation in monthly net fund flows.

We use a proprietary daily ETF NFF database which helps us avoid the use of an approximation formula. To the best of our knowledge this is the first study to use actual ETF NFF data. This is also the first study to examine daily NFF in the area of ETFs, most other studies use monthly data. We attempt to fill the void in the ETF literature by examining and identifying factors that motivate ETFs NFF changes.

There are also several studies in the area of mutual fund NFF that focus on mutual fund performance and investors timing attempts to beat the market. Most studies in the area document that investors dollar weighted returns are lower due to investors timing activities of fund flows. Dichev (2007) and Friesen and Sapp (2007) examine this phenomenon for open-end funds, whereas Dichev and $\mathrm{Yu}(2009)$ study the same issue for hedge funds.

\section{Methodology}

Because of the ETF structure, the in-kind creation and deletion of ETF units for baskets of the underlying index securities or cash, the change in the index should not have an impact on the change in the ETF NFF (Gastineau, 2004; Elton, Gruber, Comer and Li, 2002). The open-end fund literature documents that mutual fund flows are serially correlated (Ippolito, 1992; Warther, 1995). Because of the in-kind creation and redemption feature of ETFs, ETF NFF might be also serially correlated. Most studies in this area use monthly data which naturally reduces the amount of noise in the daily data (Kalaycıoğlu, 2004; Boney, Doran and Peterson, 2007). We use daily data and since this is the first study to do this we first test the following null hypotheses:

H1-0: NFF changes have no first-order autocorrelation.

A rejection of this null hypothesis would suggest that NFF changes are first-order correlated. This is precisely the null hypothesis of the Durbin-Watson Test. Therefore, we will use the Durbin-Watson Test to determine if first-order autocorrelation is present.

For example, for the Spider, the SPDR S\&P 500 ETF Trust, the oldest and most popular S\&P 500 tracking ETF with ticker symbol SPY, as it is typical for all ETFs, only "Authorized Participants" are allowed to create and redeem ETF shares from the ETF sponsor, for the Spider 50,000 units or multiples of 50,000 units at their once a day NAV. The creation and redemption is costly, for the Spider it costs the lesser of $\$ 3,000$ or 10bps of the value of one creation unit for either creation or redemption.

Considering the ETF mechanics it can be argued that only sophisticated investors would participate in the formation of ETF flows thus a major hypothesis underlying NFF formation, the sentiment hypothesis which has been examined in the mutual fund literature cannot be tested in ETFs. The sentiment hypothesis refers to the fact that unsophisticated investor sentiment might be influencing mutual fund flows (Warther, 1995), which cannot be extrapolated to ETFs because only sophisticated investors participate in the ETF flow formation. However, besides the sentiment hypothesis there are other hypotheses that have been developed to explain NFF 
formation. The other hypotheses are the feedback trader hypothesis and the contrarian investor hypothesis. The feedback trader hypothesis refers to the potential link between recent market good/bad performance and mutual fund positive/negative flows (Warther, 1995; Kalaycioğlu, 2004). The contrarian investor hypothesis proposes that a relation exists between market performance and flows but in opposite direction to the feedback trader hypothesis - that positive/negative flows into funds are due to a recent bad/good market performance (Kalaycıŏlu, 2004)

Both of these hypotheses suggest a relation of ETF NFF changes to past performance of the ETF and the market performance. Therefore, the second set of hypotheses that we test are as follows:

H2-0: NFF changes are not related to past ETF returns.

H2A-0: NFF changes are not positively related to past market performance.

H2B-0: NFF changes are not negatively related to past market performance.

A rejection of the H2-0 null hypothesis would suggest that NFF changes are related to past fund performance. A rejection of the H2A-0 null hypothesis would suggest that NFF changes are positively related to past market performance. A rejection of the H2B-0 null hypothesis would suggest that NFF changes are negatively related to past market performance.

An alternative hypothesis that we propose is based on the idea that NFF might be influenced by the existence of a tracking error of the ETF, Gastineau (2004) and Elton, Gruber, Comer and Li (2002). If a tracking error exists "Authorized Participants" would rush in and attempt to arbitrage the mispricing by either creating or redeeming ETF units, which affects the ETF NFF. Therefore, the third hypothesis that we test is as follows:

H3-0: NFF changes are not related to past ETF tracking error.

A rejection of this null hypothesis would suggest that NFF changes are related to how well the ETF tracks its underlying index.

One of the issues of having daily data is that there are a large number of observations with zero NFF using parametric OLS model would not be suitable. Therefore, we use a logistic regression to determine what factors cause the occurrence of NFF for ETFs. We use a multinomial logistic model specification, because of the nature of our dependent variable. The dependent variable, $\mathrm{P}$ (dummyNFF), accounts for the fact that there can be positive and negative NFF besides zero NFF. The dependent variable has values of one, two and three for NFF values below, equal and greater than zero, respectively. The model that we use is as follows:

$$
\begin{aligned}
& P\left(\text { dummyNFF }_{i}\right)=\beta_{0}+\beta_{1} \text { lflowtna }_{i}+\beta_{2} \text { lret }_{i}+\beta_{3} \text { lte }_{i}+\beta_{4} \text { lchgevol }_{i}+\beta_{5} \ln a v_{i} \\
& +\beta_{6} \text { lna }_{i}+\beta_{7} \text { lmkt }_{i}+\beta_{8} \text { lsmb }_{i}+\beta_{9} \text { llmml }_{i}+\beta_{10} \text { lumd }_{i}+\varepsilon_{2 i}
\end{aligned}
$$

where 'lflowtna' is the lagged value of the ratio of NFF to Total Net Assets (TNA) of the ETF, 'Iret' is the lagged ETF return, 'lte' is the lagged value of the ETF tracking error, 'lchgevol' is the lagged value of the ETF change in trading volume, 'lnav' is the lagged ETF NAV, 'Itna' is the lagged ETF Total Net Assets, 'Imkt' is the lagged excess market return, 'lsmb' is the lagged 
small-minus-big factor loading, 'lhml' is the lagged high-minus-low factor loading and 'lumd' is the lagged momentum factor. To test $\mathrm{H} 1-0, \mathrm{H} 2-0$ and $\mathrm{H} 3-0$ we use the regression coefficients $\beta_{1}$, $\beta_{2}$ and $\beta_{3}$ from equation (1), respectively. Statistically significant $\beta_{1}, \beta_{2}$ and $\beta_{3}$ coefficients would indicate rejection of $\mathrm{H} 1-0, \mathrm{H} 2-0$ and $\mathrm{H} 3-0$, respectively.

The 'lchgevol', 'Inav' and 'Itna' are control variables, so their coefficients, $\beta_{4}, \beta_{5}$ and $\beta_{6}$ would reflect factors other than the hypothesized ones. We expect that the higher the ETF lagged value of change in trading volume the higher the probability of NFF being different from zero because the highly traded ETFs would attract the most investor attention. We have no expectation for the sign of the 'lnav' variable since the participants in the creation and redemption of ETF units and thus in the formation of NFF are financial institutions not individuals to whom the unit price does not matter. We expect that the higher the ETF TNA the higher the probability of NFF being different from zero because the bigger ETFs would have more brand recognition in the market place and would attract the most investor attention.

To test the $\mathrm{H} 2 \mathrm{~A}-0$ and the $\mathrm{H} 2 \mathrm{~B}-0$ hypotheses we use the regression coefficients $\beta_{7}, \beta_{8}, \beta_{9}$ and $\beta_{10}$ from equation (1), respectively. We have no expectation for the sign of the coefficients, besides expecting them to be statistically significant. Dependent on the sign of the coefficient we can document support for either the feedback trader hypothesis or the contrarian investor hypothesis. The reason is that in good market times money would be flowing into ETFs, positive relation, and in bad market times, money would be flowing out, negative relation, based on the feedback trader hypothesis or the opposite for the contrarian investor hypothesis.

Table 2. Descriptive Statistics of Sample, Number of Days With and Without NFF Per Morningstar ETF Category.

\begin{tabular}{|l|c|c|c|c|c|c|c|}
\hline MorningstarCategory & Number of ETFs & $\begin{array}{c}\text { Mean } \\
\text { Days } \\
\text { with } \\
\text { NFF }\end{array}$ & $\begin{array}{c}\text { Mean } \\
\text { Days } \\
\text { without } \\
\text { NFF }\end{array}$ & $\begin{array}{c}\text { Min } \\
\text { Days } \\
\text { with } \\
\text { NFF }\end{array}$ & $\begin{array}{c}\text { Min } \\
\text { Days } \\
\text { without } \\
\text { NFF }\end{array}$ & $\begin{array}{c}\text { Max } \\
\text { Days } \\
\text { with } \\
\text { NFF }\end{array}$ & $\begin{array}{c}\text { Max } \\
\text { Days } \\
\text { without } \\
\text { NFF }\end{array}$ \\
\hline Blank & 371 & 138 & 124 & 1 & 0 & 841 & 838 \\
\hline Bank Loan & 3 & 840 & 835 & 840 & 834 & 840 & 836 \\
\hline Bear Market & 52 & 694 & 567 & 360 & 58 & 980 & 918 \\
\hline Commodities Agriculture & 14 & 511 & 444 & 205 & 194 & 841 & 548 \\
\hline Commodities Broad Basket & 7 & 685 & 519 & 354 & 284 & 1,125 & 760 \\
\hline Commodities Energy & 21 & 613 & 488 & 199 & 198 & 1,080 & 795 \\
\hline Commodities Industrial Metals & 6 & 494 & 440 & 424 & 381 & 576 & 530 \\
\hline Commodities Precious Metals & 16 & 658 & 578 & 205 & 202 & 1,154 & 970 \\
\hline Conservative Allocation & 2 & 424 & 403 & 424 & 393 & 424 & 413 \\
\hline Convertibles & 3 & 668 & 647 & 324 & 268 & 840 & 837 \\
\hline Diversified Emerging Mkts & 15 & 689 & 536 & 390 & 284 & 1,156 & 977 \\
\hline Diversified Pacific/Asia & 6 & 741 & 702 & 473 & 461 & 841 & 805 \\
\hline Emerging Markets Bond & 2 & 627 & 478 & 627 & 461 & 627 & 495 \\
\hline Europe Stock & 30 & 838 & 738 & 142 & 140 & 1,155 & 1,031 \\
\hline Foreign Large Blend & 637 & 580 & 142 & 140 & 1,155 & 903 \\
\hline
\end{tabular}




\begin{tabular}{|l|c|c|c|c|c|c|c|}
\hline Foreign Large Growth & 2 & 814 & 773 & 473 & 458 & 1,155 & 1,088 \\
\hline Foreign Large Value & 2 & 1,155 & 991 & 1,155 & 897 & 1,155 & 1,085 \\
\hline Foreign Small/Mid Growth & 2 & 663 & 653 & 627 & 624 & 698 & 682 \\
\hline Foreign Small/Mid Value & 5 & 670 & 624 & 424 & 415 & 841 & 804 \\
\hline High Yield Bond & 5 & 752 & 597 & 626 & 257 & 841 & 839 \\
\hline Inflation-Protected Bond & 1 & 787 & 723 & 787 & 723 & 787 & 723 \\
\hline Intermediate Government & 5 & 372 & 327 & 189 & 184 & 841 & 670 \\
\hline Intermediate-Term Bond & 10 & 794 & 686 & 620 & 472 & 841 & 812 \\
\hline Japan Stock & 10 & 798 & 738 & 142 & 142 & 1,155 & 1,134 \\
\hline Large Blend & 111 & 853 & 670 & 93 & 46 & 1,156 & 1,127 \\
\hline Large Growth & 22 & 963 & 771 & 423 & 308 & 1,156 & 1,039 \\
\hline Large Value & 21 & 899 & 673 & 93 & 91 & 1,156 & 1,018 \\
\hline Latin America Stock & 6 & 843 & 630 & 142 & 142 & 1,155 & 1,015 \\
\hline Long Government & 8 & 745 & 457 & 189 & 81 & 1,155 & 775 \\
\hline Long-Short & 4 & 589 & 554 & 424 & 390 & 786 & 762 \\
\hline Long-Term Bond & 8 & 904 & 817 & 787 & 756 & 1,155 & 878 \\
\hline Mid-Cap Blend & 26 & 868 & 689 & 403 & 369 & 1,156 & 1,125 \\
\hline
\end{tabular}

Table 2. Descriptive Statistics of Sample, Number of Days With and Without NFF Per Morningstar ETF Category, Continued.

\begin{tabular}{|l|c|c|c|c|c|c|c|}
\hline Mid-Cap Growth & 13 & 936 & 801 & 180 & 178 & 1,155 & 1,119 \\
\hline Mid-Cap Value & 11 & 940 & 808 & 217 & 215 & 1,155 & 1,137 \\
\hline Miscellaneous Sector & 1 & 627 & 263 & 627 & 263 & 627 & 263 \\
\hline Moderate Allocation & 4 & 548 & 522 & 424 & 374 & 840 & 835 \\
\hline Muni California Long & 3 & 676 & 649 & 627 & 596 & 700 & 680 \\
\hline Muni National Interm & 6 & 688 & 597 & 627 & 502 & 700 & 691 \\
\hline Muni National Long & 1 & 627 & 526 & 627 & 526 & 627 & 526 \\
\hline Muni National Short & 4 & 572 & 470 & 424 & 394 & 627 & 566 \\
\hline Muni New York Long & 1 & 627 & 617 & 627 & 617 & 627 & 617 \\
\hline Pacific/Asia ex-Japan Stk & 23 & 765 & 555 & 142 & 139 & 1,156 & 994 \\
\hline Short Government & 3 & 594 & 412 & 203 & 198 & 1,155 & 629 \\
\hline Short-Term Bond & 4 & 778 & 550 & 605 & 484 & 841 & 603 \\
\hline Small Blend & 24 & 873 & 760 & 403 & 275 & 1,155 & 1,118 \\
\hline Small Growth & 8 & 988 & 867 & 217 & 214 & 1,155 & 1,090 \\
\hline Small Value & 8 & 892 & 747 & 180 & 180 & 1,155 & 1,067 \\
\hline Specialty-Communications & 10 & 746 & 706 & 424 & 412 & 1,155 & 1,025 \\
\hline Specialty-Financial & 26 & 881 & 612 & 373 & 32 & 1,156 & 1,105 \\
\hline Specialty-Health & 41 & 660 & 591 & 93 & 93 & 1,156 & 1,056 \\
\hline Specialty-Natural Res & 47 & 780 & 609 & 373 & 75 & 1,156 & 1,030 \\
\hline
\end{tabular}




\begin{tabular}{|l|c|c|c|c|c|c|c|}
\hline Specialty-Precious Metals & 1 & 1,066 & 449 & 1,066 & 449 & 1,066 & 449 \\
\hline Specialty-Real Estate & 33 & 685 & 555 & 142 & 66 & 1,155 & 835 \\
\hline Specialty-Technology & 41 & 958 & 795 & 373 & 322 & 1,156 & 1,126 \\
\hline Specialty-Utilities & 16 & 803 & 667 & 423 & 274 & 1,156 & 1,076 \\
\hline Target-Date 2000-2014 & 1 & 379 & 369 & 379 & 369 & 379 & 369 \\
\hline Target-Date 2015-2029 & 3 & 424 & 414 & 424 & 412 & 424 & 416 \\
\hline Target-Date 2030-2044 & 3 & 399 & 387 & 378 & 362 & 424 & 414 \\
\hline Ultrashort Bond & 1 & 787 & 607 & 787 & 607 & 787 & 607 \\
\hline World Allocation & 1 & 424 & 381 & 424 & 381 & 424 & 381 \\
\hline World Bond & 19 & 564 & 528 & 195 & 194 & 841 & 767 \\
\hline World Stock & 18 & 770 & 674 & 356 & 286 & 1,155 & 1,076 \\
\hline
\end{tabular}

\section{Data and Analysis}

The NFF data are from TrimTabs.com and span the period December 22, 2005 to July 28, 2010. The daily prices, returns and volume data are from the Center for Research in Security Prices (CRSP). The market, SMB, HML and momentum factors are from Prof. Kenneth French's website: http://mba.tuck.dartmouth.edu/pages/faculty/ken.french/data_library.html. Considering the cost associated with creating and redeeming ETF units it is fair to assume that flows in and out of ETFs are not going to be that frequent. Indeed in the sample the number of days with zero ETF NFF is substantial. Out of 699,163 ETF-days there are ETF NFF only on 118,869 ETF-days or $17 \%$ of the combined sample, which means that on 580,294 ETF-days or $83 \%$ of the combined sample there are no NFF flows, in or out of the ETFs.

However, the reason is that there are 1,212 ETFs in the sample but only very few of them are popular. For example, for the Spider, out of 1,155 days there are no NFF only on 93 days or on $8 \%$ of the days, for the Diamonds (the DJIA tracking ETF, also one of the oldest and most popular ETFs) there are no NFF on 204 out of 1,155 days (18\% of the days), for the Cubes (the NASDAQ 100 tracking ETF, also one of the oldest and most popular ETFs) there are no NFF on 78 out of 1,152 days ( $6.7 \%$ of the days). If we look at relatively new but popular ETFs such as iShares S\&P 500 tracking ETF, with ticker IVV, there are no NFF on 410 out of 1,155 days (35\% of the days) or the Streettracks Gold tracking ETF, with ticker GLD, there are no NFF on 646 out of 1,155 days (56\% of the days). If we look at new but not popular ETFs such as the BLDRS Europe 100 ADR Index Fund, with ticker symbol ADRU, there are no NFF on 815 out of 841 days ( $97 \%$ of the days).

When we aggregate by the 60 Morningstar Categories the results are similar, there are popular categories and there are some that are not. Table 2 presents results for number of ETFs per category. The categories with largest concentration of ETFs are the Bear Market, Europe Stock, Foreign Large Blend, Large Blend, Specialty-Health, Specialty-Natural Res, Specialty-Real Estate and Specialty-Technology. In aggregate these categories contain approximately 33\% of the ETFs in the sample. We do not consider the Blank category because these ETFs are not categorized by Morningstar. SPY, DIA and QQQ ETFs are all in the Large Blend Morningstar Category. 
That is why in the analysis that follows we separate the sample into five groups of ETFs as described in Table 3. Group 1 consists of 19 distinct ETFs which have zero NFF on less than $25 \%$ of the observations. Group 5 has 180 distinct ETFs that have all of their NFF equal to zero in the sample. The reason might be that they have been capitalized only once at their inception which happens to be prior to the beginning of our sample, December 22, 2005.

Table 3. Descriptive Statistics of Groups Based on Number of Days with NFF.

\begin{tabular}{|r|c|c|c|c|c|}
\hline \multicolumn{1}{|c|}{ Group } & $\begin{array}{c}\text { Ratio of Days Without NFF to Total } \\
\text { Available Days }\end{array}$ & Number of ETFs & MeanRatio & MinRatio & MaxRatio \\
\hline 1 & $0<$ ratio<=0.25 & 19 & 0.12 & 0.00 & 0.24 \\
\hline 2 & $0.25<$ ratio $<=0.5$ & 47 & 0.41 & 0.26 & 0.50 \\
\hline 3 & $0.5<$ ratio<=0.75 & 132 & 0.65 & 0.50 & 0.75 \\
\hline 4 & $0.75<$ ratio<1 & 834 & 0.93 & 0.75 & 0.99 \\
\hline 5 & Ratio=1 & 180 & 1 & 1 & 1 \\
\hline
\end{tabular}

\section{A. Analysis for the Entire Sample and by Groups Based on Number of Days with NFF Different from Zero.}

Before we proceed with the estimation of the models and the hypotheses testing, in Table 4 we provide summary statistics for the NFF to TNA variable which is used as the basis for the dependent variable in the logistic regressions. The table reports the Durbin-Watson test results which reject first-order autocorrelation in all examined samples of the data, except for Group 2, and DIA and QQQ ETFs. Results up to fifth-order of correlation are identical but are not reported in the interest of brevity. These results are available upon request. The results fail to reject our H1-0 which suggests no autocorrelation in the NFF to total net assets variable for the whole sample, Groups 1, 3 and 4 and for the SPY.

Table 4. Summary Statistics for NFF to TNA.

\begin{tabular}{|c|c|c|c|c|c|c|c|c|c|}
\hline & $\begin{array}{l}\text { Whole } \\
\text { Sample }\end{array}$ & Group 1 & Group 2 & Group 3 & Group 4 & Group 5 & SPY & DIA & QQQ \\
\hline $\mathbf{N}$ & 579359 & 14297 & 32837 & 93079 & 438216 & 930 & 1154 & 1154 & 829 \\
\hline Mean & 14.32 & 0.02 & 0.00 & 0.00 & 18.94 & 0.00 & 0.00 & 0.00 & 0.00 \\
\hline Median & 0.00 & 0.00 & 0.00 & 0.00 & 0.00 & 0.00 & 0.00 & 0.00 & 0.00 \\
\hline Minimum & -1.35 & -0.97 & -0.97 & -0.93 & -1.35 & 0.00 & -0.15 & -0.20 & -0.13 \\
\hline Maximum & 7278841.38 & 49.81 & 7.02 & 102.14 & 7278841.38 & 0.00 & 0.26 & 0.34 & 0.11 \\
\hline Std Dev & 9594.15 & 0.56 & 0.11 & 0.34 & 11031.54 & 0.00 & 0.03 & 0.04 & 0.02 \\
\hline Skewness & 754.00 & 59.64 & 36.96 & 283.71 & 655.75 & . & 1.63 & 1.82 & -0.13 \\
\hline Kurtosis & 571851.52 & 4649.73 & 1904.37 & 84019.38 & 432537.48 & . & 18.70 & 19.23 & 5.10 \\
\hline $\begin{array}{l}\text { AutoCorr } \\
\text { Lag } 1\end{array}$ & 0.0000 & -0.0049 & 0.0480 & -0.0016 & 0.0000 & . & 0.0040 & -0.1904 & -0.0911 \\
\hline $\begin{array}{l}\text { DW Test } \\
\text { (p-value) }\end{array}$ & 0.5007 & 0.2787 & $<.0001$ & 0.3122 & 0.5008 & . & 0.4417 & $<.0001$ & 0.0049 \\
\hline
\end{tabular}

Even though statistically autocorrelation is present in Group 2 and DIA and QQQ, the only autocorrelation that is economically meaningful is the DIA negative autocorrelation of -0.1904 . 
The Group 2 positive autocorrelation of 0.0489 is too small to be economically meaningful and so is the QQQ negative autocorrelation of -0.0911 . These results suggest that assuming that NFF are autocorrelated at the daily frequency level is not universally true and varies across ETFs, contrary to the NFF literature using monthly data.

Table 5 provides the summary statistics for the independent variables used in the analysis.

Table 5. Summary Statistics for Independent Variables.

\begin{tabular}{|l|c|c|c|c|c|}
\hline Variable & $\mathbf{N}$ & Mean & Std Dev & Minimum & Maximum \\
\hline Iflowtna & 579359 & 14.3243 & 9594.1500 & -1.3497 & 7278841.3800 \\
\hline Iret & 579336 & 0.0001 & 0.0265 & -0.7851 & 3.6720 \\
\hline Ite & 579336 & 0.0002 & 0.2200 & -3.6720 & 166.8265 \\
\hline lchgevol & 563347 & 1.3416 & 36.2051 & -1.0000 & 11986.0000 \\
\hline Inav & 579349 & 3.5736 & 0.6836 & -1.8326 & 5.7206 \\
\hline Itna & 579349 & 18.6291 & 2.1391 & 3.2308 & 25.4439 \\
\hline Imkt & 567427 & -0.0153 & 1.8014 & -9.0000 & 11.5100 \\
\hline lsmb & 567427 & 0.0158 & 0.6819 & -3.7900 & 4.3500 \\
\hline lhml & 567427 & 0.0010 & 0.8389 & -3.3000 & 4.0100 \\
\hline lumd & 567427 & -0.0429 & 1.5294 & -8.2700 & 7.1000 \\
\hline
\end{tabular}

Table 6 provides the results of different multicollinearity checks. Panel A provides the correlogram of the independent variables. Panel B provides the Variance Inflation Factors (VIF) of the independent variables; whereas Panel $\mathrm{C}$ provides the condition numbers. Consistently, the only problematic variable is the return on the market. The relation between the ETF return and the return on the market has a correlation coefficient of 0.58 . The VIF of the return on the market is 2.28 which even though higher than the rest of the independent variables' VIFs is within the norms of reasonable coefficient. Other than the return on the market there are no other relations among the variables or independent variable to make us cautious in the interpretation of the logistic regression results due to multicollinearity.

Table 6. Multicollinearity Analysis.

Panel A. Correlation Table.

\begin{tabular}{|l|c|c|c|c|c|c|c|c|c|c|}
\hline & Iflowtna & lret & Ite & lchgevol & lnav & Itna & lmkt & lsmb & lhml & lumd \\
\hline Iflowtna & 1 & & & & & & & & & \\
\hline Iret & 0.00 & 1 & & & & & & & & \\
\hline Ite & 0.00 & -0.04 & 1 & & & & & & & \\
\hline lchgevol & 0.00 & -0.01 & 0.00 & 1 & & & & & & \\
\hline Inav & 0.00 & 0.01 & 0.00 & -0.01 & 1 & & & & & \\
\hline Itna & 0.00 & 0.00 & 0.00 & -0.03 & 0.41 & 1 & & & & \\
\hline Imkt & 0.00 & 0.58 & 0.00 & -0.01 & 0.01 & 0.00 & 1 & & & \\
\hline lsmb & 0.00 & 0.02 & 0.00 & 0.00 & 0.00 & 0.00 & 0.00 & 1 & & \\
\hline lhml & 0.00 & 0.32 & 0.00 & 0.00 & 0.01 & 0.01 & 0.55 & 0.01 & 1 & \\
\hline lumd & 0.00 & -0.33 & 0.00 & 0.00 & 0.03 & 0.01 & -0.55 & 0.02 & -0.63 & 1 \\
\hline
\end{tabular}


Panel B. Variance Inflation Factors (VIF).

\begin{tabular}{|l|c|c|c|c|c|c|c|c|c|c|}
\hline & Iflowtna & Iret & Ite & lchgevol & Inav & ltna & Imkt & lsmb & lhml & lumd \\
\hline VIF & 1.00 & 1.70 & 1.00 & 1.00 & 1.20 & 1.20 & 2.28 & 1.00 & 1.84 & 1.81 \\
\hline
\end{tabular}

Panel C. Condition Numbers.

\begin{tabular}{|c|c|c|c|c|c|c|c|c|c|c|c|c|c|}
\hline \multirow[t]{2}{*}{$\mathbf{N}$} & \multirow{2}{*}{$\begin{array}{l}\text { Eigen } \\
\text { value }\end{array}$} & & \multicolumn{11}{|c|}{ Proportion of Variation } \\
\hline & & $\begin{array}{l}\text { Condition } \\
\text { Index }\end{array}$ & Const & $\begin{array}{c}\text { Iflow } \\
\text { tna }\end{array}$ & Iret & Ite & $\begin{array}{c}\text { lchge } \\
\text { vol }\end{array}$ & Inav & Itna & Imkt & lsmb & lhml & lumd \\
\hline 1 & 2.98 & 1.00 & 0.00 & 0.00 & 0.00 & 0.00 & 0.00 & 0.00 & 0.00 & 0.00 & 0.00 & 0.00 & 0.00 \\
\hline 2 & 2.54 & 1.08 & 0.00 & 0.00 & 0.05 & 0.00 & 0.00 & 0.00 & 0.00 & 0.05 & 0.00 & 0.05 & 0.05 \\
\hline 3 & 1.01 & 1.72 & 0.00 & 0.00 & 0.00 & 0.41 & 0.00 & 0.00 & 0.00 & 0.00 & 0.57 & 0.00 & 0.00 \\
\hline 4 & 1.00 & 1.73 & 0.00 & 1.00 & 0.00 & 0.00 & 0.00 & 0.00 & 0.00 & 0.00 & 0.00 & 0.00 & 0.00 \\
\hline 5 & 1.00 & 1.73 & 0.00 & 0.00 & 0.00 & 0.11 & 0.79 & 0.00 & 0.00 & 0.00 & 0.09 & 0.00 & 0.00 \\
\hline 6 & 1.00 & 1.73 & 0.00 & 0.00 & 0.00 & 0.47 & 0.21 & 0.00 & 0.00 & 0.00 & 0.33 & 0.00 & 0.00 \\
\hline 7 & 0.77 & 1.96 & 0.00 & 0.00 & 0.37 & 0.00 & 0.00 & 0.00 & 0.00 & 0.04 & 0.01 & 0.15 & 0.15 \\
\hline 8 & 0.38 & 2.82 & 0.00 & 0.00 & 0.00 & 0.00 & 0.00 & 0.00 & 0.00 & 0.01 & 0.00 & 0.68 & 0.76 \\
\hline 9 & 0.31 & 3.12 & 0.00 & 0.00 & 0.57 & 0.00 & 0.00 & 0.00 & 0.00 & 0.90 & 0.00 & 0.11 & 0.03 \\
\hline 10 & 0.02 & 12.12 & 0.13 & 0.00 & 0.00 & 0.00 & 0.00 & 0.97 & 0.06 & 0.00 & 0.00 & 0.00 & 0.00 \\
\hline 11 & 0.01 & 22.22 & 0.87 & 0.00 & 0.00 & 0.00 & 0.00 & 0.03 & 0.94 & 0.00 & 0.00 & 0.00 & 0.00 \\
\hline
\end{tabular}

In Table 7 we report the results of the multinomial logistic regression as defined in equation (1). H1-0 is rejected for the Group 2 ETFs for both positive and negative NFF, but the model fails to reject H1-0 in the rest of the samples. H2-0 is rejected in all Groups of ETFs but is failed to be rejected for the Group 3 negative NFF, SPY, DIA and QQQ. H3-0 is rejected for negative NFF of Group 2 and negative NFF of SPY, but is failed to be rejected for the rest of the samples.

Table 7. Multinomial Logistic Regression Results, Dependent Variable -p(DummyNFF), with Values of One if NFF is Negative, Value of Two if NFF is Zero, and Value of Three if NFF is Positive.

\begin{tabular}{|c|c|c|c|c|c|c|c|c|c|c|c|}
\hline & D1 & \multicolumn{2}{|c|}{ whole sample } & \multicolumn{2}{|c|}{ Group 1} & \multicolumn{2}{|c|}{ Group 2} & \multicolumn{2}{|c|}{ Group 3} & \multicolumn{2}{|c|}{ Group 4} \\
\hline Intercept & 1 & -13.0808 & $<.0001$ & -3.5469 & $<.0001$ & -3.7057 & $<.0001$ & -4.9382 & $<.0001$ & -9.1383 & $<.0001$ \\
\hline Iflowtna & 1 & 0.0000 & 0.8880 & -0.1190 & 0.1163 & -0.6590 & 0.0101 & -0.0864 & 0.6534 & -0.0001 & 0.9227 \\
\hline Iflowtna & 3 & 0.0000 & 0.8492 & 0.0245 & 0.4858 & 0.2383 & 0.0328 & 0.0166 & 0.3944 & -0.0009 & 0.8767 \\
\hline Iret & 3 & 1.4030 & $<.0001$ & 8.2863 & 0.0002 & 2.6353 & 0.0013 & 0.9538 & 0.0715 & 0.8218 & 0.0032 \\
\hline Ite & 1 & 0.0070 & 0.8559 & 2.8773 & 0.2779 & 18.2629 & 0.0018 & 1.1242 & 0.2105 & -0.0002 & 0.9977 \\
\hline Ite & 3 & 0.0088 & 0.7381 & 3.3998 & 0.2018 & -2.2335 & 0.3437 & 1.0472 & 0.1685 & 0.0013 & 0.9735 \\
\hline lchgevol & 1 & 0.0007 & $<.0001$ & 0.0001 & 0.7820 & -0.0027 & 0.5555 & 0.0000 & 0.9576 & 0.0008 & $<.0001$ \\
\hline
\end{tabular}




\begin{tabular}{|l|c|c|c|c|c|c|c|c|c|c|c|}
\hline Inav & $\mathbf{3}$ & $\mathbf{- 0 . 1 9 9 3}$ & $<.0001$ & $\mathbf{- 0 . 6 4 8 6}$ & $<.0001$ & $\mathbf{- 0 . 4 5 6 6}$ & $<.0001$ & $\mathbf{- 0 . 0 4 9 5}$ & $\mathbf{0 . 0 0 0 1}$ & $\mathbf{- 0 . 0 9 0 5}$ & $<.0001$ \\
\hline Itna & $\mathbf{1}$ & $\mathbf{0 . 6 0 3 6}$ & $<.0001$ & $\mathbf{0 . 3 3 4 3}$ & $<.0001$ & $\mathbf{0 . 1 9 9 7}$ & $<.0001$ & $\mathbf{0 . 2 1 2 9}$ & $<.0001$ & $\mathbf{0 . 3 4 7 0}$ & $<.0001$ \\
\hline Itna & $\mathbf{3}$ & $\mathbf{0 . 5 6 4 7}$ & $<.0001$ & $\mathbf{0 . 3 7 1 1}$ & $<.0001$ & $\mathbf{0 . 2 4 3 2}$ & $<.0001$ & $\mathbf{0 . 2 0 4 9}$ & $<.0001$ & $\mathbf{0 . 3 5 6 2}$ & $<.0001$ \\
\hline Imkt & $\mathbf{1}$ & $\mathbf{- 0 . 0 2 6 6}$ & $<.0001$ & 0.0354 & 0.2577 & $\mathbf{- 0 . 0 2 6 3}$ & $\mathbf{0 . 0 6 3 1}$ & $\mathbf{- 0 . 0 5 3 3}$ & $<.0001$ & $\mathbf{- 0 . 0 2 8 6}$ & $\mathbf{0 . 0 0 0 6}$ \\
\hline Imkt & $\mathbf{3}$ & -0.0031 & 0.4216 & 0.0082 & 0.7917 & -0.0019 & 0.8773 & -0.0049 & 0.5416 & $\mathbf{- 0 . 0 1 0 3}$ & $\mathbf{0 . 0 5 8 4}$ \\
\hline Ismb & $\mathbf{1}$ & $\mathbf{- 0 . 0 2 2 3}$ & $\mathbf{0 . 0 0 9 0}$ & -0.0565 & 0.1972 & 0.0261 & 0.2469 & -0.0010 & 0.9514 & $\mathbf{- 0 . 0 3 8 8}$ & $\mathbf{0 . 0 0 4 8}$ \\
\hline lsmb & $\mathbf{3}$ & -0.0044 & 0.5211 & 0.0151 & 0.7260 & -0.0075 & 0.7048 & -0.0033 & 0.7858 & -0.0031 & 0.7640 \\
\hline Ihml & $\mathbf{1}$ & $\mathbf{- 0 . 0 4 1 5}$ & $<.0001$ & $\mathbf{- 0 . 1 5 0 0}$ & $\mathbf{0 . 0 0 2 2}$ & $\mathbf{- 0 . 0 9 9 2}$ & $<.0001$ & $\mathbf{- 0 . 0 4 5 6}$ & $\mathbf{0 . 0 0 8 3}$ & -0.0242 & 0.1067 \\
\hline Ihml & $\mathbf{3}$ & $\mathbf{- 0 . 0 2 1 6}$ & $\mathbf{0 . 0 0 4 2}$ & $\mathbf{- 0 . 1 4 8 1}$ & $\mathbf{0 . 0 0 2 3}$ & $\mathbf{- 0 . 0 5 6 5}$ & $\mathbf{0 . 0 1 0 8}$ & $\mathbf{- 0 . 0 2 9 6}$ & $\mathbf{0 . 0 3 1 3}$ & -0.0066 & 0.5551 \\
\hline lumd & $\mathbf{1}$ & $\mathbf{- 0 . 0 3 4 5}$ & $<.0001$ & -0.0224 & 0.3992 & $\mathbf{- 0 . 0 6 5 3}$ & $<.0001$ & $\mathbf{- 0 . 0 4 8 8}$ & $<.0001$ & $\mathbf{- 0 . 0 2 3 5}$ & $\mathbf{0 . 0 0 3 8}$ \\
\hline lumd & $\mathbf{3}$ & $\mathbf{- 0 . 0 1 4 4}$ & $\mathbf{0 . 0 0 0 4}$ & 0.0177 & 0.5027 & $\mathbf{- 0 . 0 3 4 3}$ & $\mathbf{0 . 0 0 4 8}$ & $\mathbf{- 0 . 0 1 8 3}$ & $\mathbf{0 . 0 1 4 6}$ & $\mathbf{- 0 . 0 1 2 2}$ & $\mathbf{0 . 0 4 3 9}$ \\
\hline & & & & & & & & & & & \\
\hline $\mathbf{N}$ & & & 551609 & & 14050 & & 32234 & & 91310 & & 413394 \\
\hline
\end{tabular}

Table 7. Multinomial Logistic Regression Results, Dependent Variable - p(DummyNFF), with Values of One if NFF is Negative, Value of Two if NFF is Zero, and Value of Three if NFF is Positive, Continued.

\begin{tabular}{|l|c|c|c|c|c|c|c|}
\hline & \multicolumn{2}{|c|}{ SPY } & \multicolumn{2}{c|}{ DIA } & \multicolumn{2}{c|}{ QQQ } \\
\hline & $\mathbf{D 1}$ & coef & $\mathrm{p}$-value & coef & $\mathrm{p}$-value & coef & $\mathrm{p}$-value \\
\hline Intercept & $\mathbf{1}$ & $\mathbf{- 6 7 . 7 2 2 2}$ & $\mathbf{0 . 0 0 1 1}$ & -9.5379 & 0.4555 & $\mathbf{2 2 0 . 8 0 0 0}$ & $<.0001$ \\
\hline Intercept & $\mathbf{3}$ & $\mathbf{- 9 2 . 7 7 4 3}$ & $<.0001$ & $\mathbf{- 4 1 . 0 5 6 4}$ & $\mathbf{0 . 0 0 1 4}$ & 85.6817 & 0.1130 \\
\hline Iflowtna & $\mathbf{1}$ & -2.7560 & 0.5556 & 0.9867 & 0.6288 & 2.0794 & 0.7774 \\
\hline lflowtna & $\mathbf{3}$ & -1.3015 & 0.7803 & -2.5882 & 0.2215 & 0.8293 & 0.9093 \\
\hline Iret & $\mathbf{1}$ & 12.6093 & 0.8135 & 35.8746 & 0.1245 & 9.2854 & 0.7578 \\
\hline Iret & $\mathbf{3}$ & 24.3262 & 0.6500 & 6.7034 & 0.7743 & 23.8892 & 0.4254 \\
\hline Ite & $\mathbf{1}$ & $\mathbf{- 1 4 3 . 5 0 0 0}$ & $\mathbf{0 . 0 4 1 8}$ & -73.9256 & 0.1842 & 0.3778 & 0.9336 \\
\hline Ite & $\mathbf{3}$ & -41.4015 & 0.4479 & -79.5687 & 0.1526 & 0.9722 & 0.8275 \\
\hline Ichgevol & $\mathbf{1}$ & 0.0027 & 0.9926 & -0.0152 & 0.8405 & -0.2012 & 0.6831 \\
\hline Ichgevol & $\mathbf{3}$ & 0.0019 & 0.9949 & -0.0085 & 0.5030 & 0.1503 & 0.7557 \\
\hline Inav & $\mathbf{1}$ & $\mathbf{- 2 . 8 6 9 5}$ & $\mathbf{0 . 0 0 0 6}$ & $\mathbf{- 2 . 2 8 8 3}$ & $<.0001$ & $\mathbf{5 . 5 8 1 8}$ & $\mathbf{0 . 0 5 8 1}$ \\
\hline Inav & $\mathbf{3}$ & $\mathbf{- 2 . 9 5 3 8}$ & $\mathbf{0 . 0 0 0 4}$ & $\mathbf{- 1 . 8 1 2 6}$ & $\mathbf{0 . 0 0 1 7}$ & -0.2509 & 0.9312 \\
\hline Itna & $\mathbf{1}$ & $\mathbf{3 . 3 4 8 8}$ & $<.0001$ & $\mathbf{0 . 9 3 0 0}$ & $\mathbf{0 . 0 9 4 3}$ & $\mathbf{- 1 0 . 1 6 9 1}$ & $\mathbf{0 . 0 0 0 2}$ \\
\hline Itna & $\mathbf{3}$ & $\mathbf{4 . 3 6 7 9}$ & $<.0001$ & $\mathbf{2 . 2 1 7 3}$ & $<.0001$ & -3.4985 & 0.1954 \\
\hline Imkt & $\mathbf{1}$ & -0.0951 & 0.8587 & -0.3390 & 0.1289 & -0.2069 & 0.5469 \\
\hline Imkt & $\mathbf{3}$ & -0.1015 & 0.8498 & -0.1251 & 0.5717 & -0.2441 & 0.4745 \\
\hline Ismb & $\mathbf{1}$ & -0.3581 & 0.1280 & 0.0732 & 0.6318 & -0.1973 & 0.4530 \\
\hline Ismb & $\mathbf{3}$ & -0.2171 & 0.3563 & 0.1762 & 0.2471 & -0.1314 & 0.6110 \\
\hline lhml & $\mathbf{1}$ & $\mathbf{- 0 . 4 7 8 9}$ & $\mathbf{0 . 0 6 2 4}$ & -0.0502 & 0.7647 & -0.0778 & 0.8001 \\
\hline lhml & $\mathbf{3}$ & -0.3974 & 0.1220 & -0.0169 & 0.9192 & 0.1087 & 0.7196 \\
\hline lumd & $\mathbf{1}$ & -0.1231 & 0.3681 & 0.0152 & 0.8649 & -0.0875 & 0.5715 \\
\hline lumd & $\mathbf{3}$ & 0.0087 & 0.9496 & 0.0136 & 0.8787 & -0.0168 & 0.9122 \\
\hline & & & & & & & \\
\hline
\end{tabular}




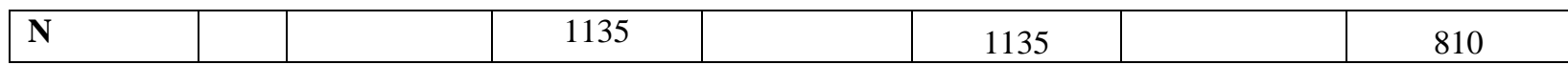

The size control variables are consistently statistically significant. Again, as expected the TNA coefficient is positive and statistically significant, suggesting that the larger the ETF's TNA the higher the probability of a positive or negative NFF. The NAV coefficient is negative suggesting that the smaller the ETF's NAV the higher the probability of a positive or negative NFF. QQQ ETF is again the only exception, with positive and significant NAV coefficient and statistically significant but negative NAV coefficient for the negative NFF case and non-significant coefficients for the positive NFF case.

The statistical significance of market changes and Fama-French factor loadings coefficients vary by group of ETFs. The whole sample and ETF Groups 2, 3 and 4 results suggest that negative ETF flows are related to good market performance. These findings reject H2B-0 and are in support of the contrarian hypothesis. The whole sample results and individual ETF Group results (vary by group) for HML, SMB and the momentum factors for negative NFF are also statistically significant also rejecting H2B-0 and in support of the contrarian hypothesis. The SPY, DIA and QQQ results related to the contrarian and feedback trader hypotheses do not exhibit patterns with the exception of the SPY HML factor which has a statistically significant coefficient for negative $\mathrm{NFF}$ again. We fail to find evidence rejecting $\mathrm{H} 2 \mathrm{~A}-0$.

\section{B. Analysis by Select Group of Morningstar Categories of ETFs.}

We also perform the analysis based on equation (1) by Morningstar Categories of ETFs. However, in Table 8 we report the results only for a select group of ETFs in a Morningstar Category. We provide results for the categories with highest number of ETFs. The group of ETFs "Not Categorized by Morningstar" has the highest number of ETFs but we do not report these results. The rest are not reported in the interest of brevity but are available upon request.

Table 8. Multinomial Logistic Regression Results, Dependent Variable - p(DummyNFF), with Values of One if NFF is Negative, Value of Two if NFF is Zero, and Value of Three if NFF is Positive, Select Morningstar Categories.

\begin{tabular}{|l|c|c|c|c|c|c|c|c|c|}
\hline & & \multicolumn{2}{|c|}{ Bear Market } & \multicolumn{2}{c|}{ Europe Stock } & \multicolumn{2}{c|}{ Foreign Large Blend } & \multicolumn{2}{c|}{ Large Blend } \\
\hline & & coef & p-value & coef & p-value & coef & p-value & coef & p-value \\
\hline Intercept & $\mathbf{1}$ & $\mathbf{- 1 5 . 8 7 4 4}$ & $<.0001$ & $\mathbf{- 8 . 2 2 3 2}$ & $<.0001$ & $\mathbf{- 8 . 9 6 2 9}$ & $<.0001$ & $\mathbf{- 1 5 . 5 9 1 1}$ & $<.0001$ \\
\hline Intercept & $\mathbf{3}$ & $\mathbf{- 1 5 . 5 9 6 9}$ & $<.0001$ & $\mathbf{- 1 0 . 6 2 9 0}$ & $<.0001$ & $\mathbf{- 9 . 7 5 1 6}$ & $<.0001$ & $\mathbf{- 1 3 . 9 3 0 5}$ & $<.0001$ \\
\hline Iflowtna & $\mathbf{1}$ & $\mathbf{1 . 2 7 7 4}$ & $\mathbf{0 . 0 0 2 4}$ & $\mathbf{0 . 0 7 7 0}$ & $\mathbf{0 . 7 9 1 7}$ & $\mathbf{0 . 0 0 0 0}$ & $\mathbf{0 . 9 9 9 4}$ & $\mathbf{0 . 3 1 5 6}$ & $<.0001$ \\
\hline Iflowtna & $\mathbf{3}$ & 0.4856 & 0.3643 & 0.2201 & 0.2362 & 0.0000 & 0.9882 & $\mathbf{0 . 3 1 2 2}$ & $<.0001$ \\
\hline Iret & $\mathbf{1}$ & -0.6802 & 0.8308 & $\mathbf{- 5 . 6 0 8 5}$ & $\mathbf{0 . 0 3 8 3}$ & 0.2399 & 0.9350 & 1.6180 & 0.2077 \\
\hline Iret & $\mathbf{3}$ & -3.4654 & 0.1731 & $\mathbf{4 . 4 9 3 2}$ & $\mathbf{0 . 0 5 5 5}$ & -0.1225 & 0.9514 & -0.1989 & 0.8572 \\
\hline Ite & $\mathbf{1}$ & $\mathbf{- 3 . 4 0 7 9}$ & $\mathbf{0 . 0 2 5 5}$ & 12.1429 & 0.1159 & $\mathbf{2 0 . 3 5 0 6}$ & $\mathbf{0 . 0 5 4 8}$ & 1.1695 & 0.1199 \\
\hline Ite & $\mathbf{3}$ & -0.8472 & 0.6920 & $\mathbf{2 7 . 7 8 9 5}$ & $<.0001$ & $\mathbf{1 5 . 6 2 9 3}$ & $\mathbf{0 . 0 3 0 8}$ & 1.0502 & 0.1335 \\
\hline Ichgevol & $\mathbf{1}$ & 0.0089 & 0.1222 & 0.0016 & 0.3901 & $\mathbf{0 . 0 0 1 0}$ & $\mathbf{0 . 0 0 3 2}$ & $\mathbf{0 . 0 0 1 9}$ & $\mathbf{0 . 0 0 0 3}$ \\
\hline Ichgevol & $\mathbf{3}$ & 0.0033 & 0.6961 & 0.0020 & 0.1353 & -0.0010 & 0.6765 & $\mathbf{0 . 0 0 1 6}$ & $\mathbf{0 . 0 0 2 3}$ \\
\hline Inav & $\mathbf{1}$ & 0.0242 & 0.8500 & $\mathbf{- 0 . 6 8 6 0}$ & $<.0001$ & $\mathbf{- 1 . 1 2 3 3}$ & $<.0001$ & $\mathbf{- 1 . 2 5 5 8}$ & $<.0001$ \\
\hline Inav & $\mathbf{3}$ & -0.0137 & 0.8893 & $\mathbf{- 0 . 3 9 5 9}$ & $<.0001$ & $\mathbf{- 0 . 1 6 4 3}$ & $\mathbf{0 . 0 1 7 1}$ & $\mathbf{- 1 . 0 7 9 0}$ & $<.0001$ \\
\hline
\end{tabular}




\begin{tabular}{|l|c|c|c|c|c|c|c|c|c|}
\hline Itna & $\mathbf{1}$ & $\mathbf{0 . 6 9 1 8}$ & $<.0001$ & $\mathbf{0 . 3 9 7 2}$ & $<.0001$ & $\mathbf{0 . 4 7 9 1}$ & $<.0001$ & $\mathbf{0 . 9 2 5 2}$ & $<.0001$ \\
\hline Itna & $\mathbf{3}$ & $\mathbf{0 . 7 1 5 6}$ & $<.0001$ & $\mathbf{0 . 4 9 3 2}$ & $<.0001$ & $\mathbf{0 . 4 0 4 7}$ & $<.0001$ & $\mathbf{0 . 8 3 1 5}$ & $<.0001$ \\
\hline lmkt & $\mathbf{1}$ & 0.0435 & 0.3521 & -0.0206 & 0.5870 & 0.0189 & 0.6671 & $\mathbf{- 0 . 0 3 8 3}$ & $\mathbf{0 . 0 1 6 5}$ \\
\hline lmkt & $\mathbf{3}$ & $\mathbf{- 0 . 0 6 3 2}$ & $\mathbf{0 . 0 8 8 2}$ & $\mathbf{- 0 . 0 7 5 0}$ & $\mathbf{0 . 0 2 2 0}$ & 0.0328 & 0.2632 & 0.0138 & 0.3141 \\
\hline lsmb & $\mathbf{1}$ & $\mathbf{- 0 . 1 7 6 7}$ & $\mathbf{0 . 0 1 0 7}$ & $\mathbf{- 0 . 1 4 0 9}$ & $\mathbf{0 . 0 0 3 0}$ & -0.0128 & 0.8232 & -0.0300 & 0.1331 \\
\hline lsmb & $\mathbf{3}$ & -0.0101 & 0.8576 & 0.0071 & 0.8565 & -0.0265 & 0.4778 & 0.0031 & 0.8573 \\
\hline lhml & $\mathbf{1}$ & $\mathbf{0 . 1 5 8 2}$ & $\mathbf{0 . 0 3 5 1}$ & 0.0569 & 0.2790 & -0.0519 & 0.4117 & $\mathbf{- 0 . 0 4 6 2}$ & $\mathbf{0 . 0 3 6 8}$ \\
\hline lhml & $\mathbf{3}$ & -0.0432 & 0.4790 & 0.0277 & 0.5279 & -0.0387 & 0.3383 & -0.0150 & 0.4323 \\
\hline lumd & $\mathbf{1}$ & 0.0618 & 0.1395 & 0.0044 & 0.8802 & $\mathbf{0 . 0 9 6 8}$ & $\mathbf{0 . 0 0 5 6}$ & $\mathbf{- 0 . 0 2 8 5}$ & $\mathbf{0 . 0 1 8 2}$ \\
\hline lumd & $\mathbf{3}$ & 0.0004 & 0.9915 & -0.0354 & 0.1423 & 0.0245 & 0.2691 & 0.0158 & 0.1323 \\
\hline & & & & & & & & & \\
\hline $\mathbf{N}$ & & & 11770 & & 23265 & & 24125 & & 85484 \\
\hline
\end{tabular}

Table 8. Multinomial Logistic Regression Results, Dependent Variable - p(DummyNFF), with Values of One if NFF is Negative, Value of Two if NFF is Zero, and Value of Three if NFF is Positive, Select Morningstar Categories, Continued.

\begin{tabular}{|c|c|c|c|c|c|c|c|c|c|}
\hline & & \multicolumn{2}{|c|}{ Specialty-Health } & \multicolumn{2}{|c|}{ Specialty-Natural Res } & \multicolumn{2}{|c|}{ Specialty-Real Estate } & \multicolumn{2}{|c|}{ Specialty-Technology } \\
\hline & & coef & p-value & coef & p-value & coef & p-value & coef & $\mathrm{p}$-value \\
\hline Intercept & 1 & -12.7298 & $<.0001$ & -13.2518 & $<.0001$ & -16.7214 & $<.0001$ & -16.2600 & $<.0001$ \\
\hline Intercept & 3 & -11.5243 & $<.0001$ & -10.5995 & $<.0001$ & -14.4600 & $<.0001$ & -16.2497 & $<.0001$ \\
\hline Iflowtna & 1 & 1.6143 & 0.0005 & 0.0000 & 0.9510 & -0.9763 & 0.2554 & 0.8789 & 0.0573 \\
\hline Iflowtna & 3 & 1.4881 & 0.0012 & 0.0000 & 0.9392 & 0.0368 & 0.9524 & 1.2543 & 0.0008 \\
\hline Iret & 1 & -10.9429 & 0.0012 & -1.8566 & 0.1483 & -1.1736 & 0.5146 & -3.4141 & 0.0931 \\
\hline Iret & 3 & 2.7172 & 0.3856 & 3.4483 & 0.0011 & 1.1941 & 0.3815 & 4.2732 & 0.0164 \\
\hline Ite & 1 & 11.8304 & 0.0309 & -1.0960 & 0.4657 & 1.2998 & 0.7517 & 1.9003 & 0.5444 \\
\hline Ite & 3 & 8.8533 & 0.1204 & -0.4655 & 0.7033 & 1.6189 & 0.5867 & -5.2044 & 0.0299 \\
\hline Ichgevol & 1 & 0.0028 & 0.0094 & 0.0000 & 0.9994 & 0.0008 & 0.6439 & 0.0029 & 0.1552 \\
\hline lchgevol & 3 & 0.0030 & 0.0017 & -0.0001 & 0.9451 & 0.0003 & 0.7209 & 0.0051 & $<.0001$ \\
\hline Inav & 1 & -0.7433 & $<.0001$ & -0.3328 & $<.0001$ & -0.0952 & 0.1123 & -0.0148 & 0.6910 \\
\hline Inav & 3 & -0.8187 & $<.0001$ & -0.3901 & $<.0001$ & -0.0795 & 0.0794 & 0.1990 & $<.0001$ \\
\hline Itna & 1 & 0.6734 & $<.0001$ & 0.6359 & $<.0001$ & 0.7658 & $<.0001$ & 0.7309 & $<.0001$ \\
\hline Itna & 3 & 0.6382 & $<.0001$ & 0.5326 & $<.0001$ & 0.6821 & $<.0001$ & 0.7054 & $<.0001$ \\
\hline lmkt & 1 & -0.0004 & 0.9902 & -0.0259 & 0.2773 & -0.0259 & 0.3995 & -0.0002 & 0.9948 \\
\hline Imkt & 3 & -0.0622 & 0.0385 & -0.0336 & 0.0814 & -0.0035 & 0.8822 & -0.0065 & 0.7765 \\
\hline lsmb & 1 & 0.0386 & 0.4082 & 0.0792 & 0.0090 & -0.0058 & 0.9042 & 0.0091 & 0.7844 \\
\hline lsmb & 3 & -0.0344 & 0.4179 & 0.0012 & 0.9621 & -0.0001 & 0.9987 & -0.0325 & 0.2680 \\
\hline Ihml & 1 & -0.0358 & 0.4962 & -0.0131 & 0.6931 & 0.0138 & 0.7885 & -0.0124 & 0.7372 \\
\hline lhml & 3 & 0.0215 & 0.6523 & -0.0844 & 0.0021 & -0.0368 & 0.3605 & -0.0376 & 0.2496 \\
\hline lumd & 1 & -0.0536 & 0.0607 & -0.0397 & 0.0261 & -0.0341 & 0.2300 & -0.0077 & 0.6964 \\
\hline lumd & 3 & -0.0313 & 0.2316 & -0.0339 & 0.0220 & 0.0081 & 0.7150 & -0.0396 & 0.0231 \\
\hline $\mathbf{N}$ & & & 20440 & & 33278 & & 17904 & & 36183 \\
\hline
\end{tabular}


The table reports results of the multinomial logistic regression per select group of Morningstar Categories based on equation (1). The results again vary per group. H1-0 is rejected for negative NFF of Bear Market, Europe Stock, Foreign Large Blend, Large Blend, Specialty-Health and Specialty-Technology, but is not rejected for neither positive nor negative NFF for SpecialtyNatural Res and Specialty-Real Estate. H1-0 is rejected for positive NFF of Large Blend, Specialty-Health and Specialty Technology ETFs. H2-0 is rejected for both positive and negative NFF for Europe Stock ETFs and Specialty-Technology ETFs, but only for negative NFF for Specialty-Health and for positive NFF for Specialty-Natural Res ETFs. For the rest of the select group of ETFs H2-0 is not rejected. H3-0 is rejected for both positive and negative NFF for only Foreign Large Blend ETFs, and it is also rejected for negative NFF for Bear Market ETFs and Specialty-Health ETFs, and positive NFF for Europe Stock ETFs and Specialty-Technology ETFs. The size control variables are again consistently statistically significant.

The statistical significance of market changes and Fama-French factor loadings coefficients again vary by group. The Bear Market, Europe Stock, Specialty-Health and Specialty-Natural Resources ETFs results suggest that positive ETF flows are negatively related to good market performance. Whereas the Bear Market ETFs negative NFF seem to be positively related to the HML factor. The same applies to the Foreign Large Blend ETFs whose negative NFF are positively related to the momentum factor. However, negative NFF of Large Blend, SpecialtyHealth and Specialty-Natural Resources ETFs seem to be negatively related to the HML and momentum factors. These findings are again somewhat rejecting $\mathrm{H} 2 \mathrm{~B}-0$ and in support of the contrarian hypothesis. We fail to find evidence rejecting $\mathrm{H} 2 \mathrm{~A}-0$.

\section{Conclusion}

In this study we attempt to identify the factors that impact ETF NFF. To the best of our knowledge this is the first study to examine this issue. We document that autocorrelation at the daily frequency is not universally present for the 1,212 ETFs that we study, despite the fact that this is the case in the monthly data. We also fail to find support for the feedback trading hypothesis but document some support for the contrarian investor hypotheses on daily basis, even though the opposite is found for both in the prior literature monthly data. Also, using the daily data we cannot conclude that tracking error prompts arbitrage activity by using creation and redemption of ETF units.

One of the appealing features of ETFs, in comparison to open-end funds, is their intradaily price adjustment. This means that when analyzing ETF NFF and their response to arbitrage opportunities even when using the higher frequency of daily observations in this study might not be sufficient. This is the first study, to the best of our knowledge, of examining the higher daily frequency of NFF, all of the rest of the studies use monthly or quarterly data. However, considering the intradaily ETF price changes and arbitrage opportunities, even the daily data might not be sufficient. Therefore, it would be valuable to examine NFF on intradaily basis. Naturally, this would be possible once such data become available. 


\section{References}

Alexander C. and Barbosa A. (2005), "The Spider in the hedge", ISMA Centre Finance Discussion Paper No. DP2005-05. Available at SSRN: http://ssrn.com/abstract=706261. Accessed 15 Mar 2001.

Boney,V. R., Doran, J. S. and Peterson, D. R. (2007), “The effect of the Spider exchange traded fund on the demand for S\&P index mutual funds", ETFs and Indexing, Vol. 2007, pp. 61-74.

Dichev, I. D. (2007), "What are stock investors' actual historical returns? Evidence from dollarweighted returns", The American Economic Review, Vol. 97, pp. 386-401.

Dichev, I. D. and Yu, G. (2009), "Higher risk, lower returns: What hedge fund investors really earn", Available at SSRN: http://ssrn.com/abstract=1354070. Accessed 15 Mar 2001.

Edelen, R. M. (1999), "Investor flows and the assessed performance of open-end mutual funds", Journal of Financial Economics, Vol. 53, pp. 439-466.

Elton E.J., Gruber, M.J., Comer, G. and Li, K. (2002), “Spider: Where are the bugs?”, Journal of Business, Vol. 75, pp. 453-472.

Fassas, Athanasios P. (2014), "Tracking Ability of ETFs: Physical versus Synthetic Replication." The Journal of Index Investing, Vol. 5, pp. 2, pp. 9-20.

Friesen, G. C. and Sapp, T. (2007), "Mutual fund flows and investor returns: An empirical examination of fund investor timing ability", Journal of Banking \& Finance, Vol. 31, pp. 27962816.

Gastineau, G. L. (2004), “The benchmark index ETF performance problem: A simple solution", Journal of Portfolio Management, Vol. 2004, pp. 62-69.

Greene, J. T., and Hodges, C. W. (2002), “The dilution impact of daily fund flows on open-end mutual funds", Journal of Financial Economics, Vol. 65, pp. 131-158.

Gruber, M. J. (1996), “Another puzzle: The growth in actively managed mutual funds”, The Journal of Finance, Vol. 51, pp. 783-810.

Ippolito, R. A. (1992), "Consumer reaction to measures of poor quality: Evidence from the mutual fund industry", Journal of Law and Economics, Vol. 35, pp. 45-70.

Kalaycioğlu, S. (2004), “Exchange traded fund flows”, University of Rochester Simon Graduate School of Business, Working Paper. Retrieved from http://ssrn.com/abstract=881108. Accessed 15 Mar 2001.

Sirri, E. R. and Tufano, P. (1998), "Costly search and mutual fund flows", The Journal of Finance, Vol. 53, pp. 1589-1622. 
Warther, V. A. (1995), “Aggregate mutual fund flows and security returns”, Journal of Financial Economics, Vol. 39, pp. 209-235.

Yu, L. (2005), "Basket securities, price formation, and informational efficiency", Working Paper. Available at SSRN: http://ssrn.com/abstract=862604. Accessed 15 Mar 2001. 